\title{
Particulate matter mass concentrations produced from pavement surface abrasion
}

\author{
Dasa Fullova ${ }^{1, *}$, Daniela Durcanska ${ }^{1}$, and Jitka Hegrova ${ }^{2}$ \\ ${ }^{1}$ University of Žilina, Faculty of Civil Engineering, Department of Highway Engineering, \\ Univerzitná 1, 01026 Žilina, Slovakia \\ ${ }^{2}$ Transport Research Centre, Division of transport infrastructure and the environment, Líšeňská 33a, \\ 63600 Brno, Czech Republic
}

\begin{abstract}
According to the latest findings particulate matter belong to the most significant pollutants in Europe together with ground-level ozone O3 and nitrogen dioxide NO2. Road traffic is one of the main sources of particulate matter. Traffic volume has unpleasant impact on longevity of the pavements and also on the environment. Vehicle motions cause mechanical wearing of the asphalt pavement surface - wearing course by vehicle tyres. The paper deals with abrasion of bituminous wearing courses of pavements. The asphalt mixtures are compared in terms of mechanically separated particulate matter. The samples of asphalt mixtures were rutted in wheel tracking machine. The particulate matter measurements were performed in laboratory conditions. The experimental laboratory measurements make it possible to sample particulates without contamination from exhaust emissions, abraded particles from vehicles, resuspension of road dust and climate affects. The paper offers partial results of measurements on six trial samples of asphalt mixtures with different composition. It presents particulate matter morphology and the comparison of rutted asphalt samples in terms of PM mass concentrations and chemical composition.
\end{abstract}

\section{Introduction}

Non-exhaust emissions of particulate matter from road traffic may originate from abrasion of vehicle parts (tyres, brake linings, clutch and bodywork) or from pavement surface abrasion and also from resuspension of dust 1,1 . The aim of this research is to monitor the abraded particulate matter from non-combustion processes - from abrasion of pavement surface. A differentiation between PM emissions from road pavement abrasion and resuspension is very difficult due to their similar elemental composition 2 . For this reason, the measurements are performed in the laboratory at the Department of Highway Engineering. The issue of abraded particulate matter from pavement surfaces and the contribution of those emissions to air pollution is mostly solved in the Nordic countries 3, $4,5,6,7$.

*Corresponding author: dasa.fullova@,fstav.uniza.sk 
Laboratory particle sampling makes it possible to sample particulates with very low contamination from surrounding sources and meteorological factors. An important phase of the research is to determine chemical elements in the collected particulate matter and to confront it with the representation of these elements in the chemical composition of the asphalt mixture. The next step is to attempt to determine the share of the mechanical separation of PM from the pavement by evaluating the chemical composition of the materials used for studied asphalt mixtures of wearing courses and subsequently collected particulate matter PM. The research is aimed at finding dependence between the composition of asphalt mixture and collected PM.

\section{Methodology of laboratory tests}

The asphalt mixture samples of wearing courses are used for laboratory measurements. The used asphalt mixture samples (plates of size $320 \times 260 \mathrm{~mm}$ and thicknesses of $40 \mathrm{~mm}$ ) are rutted in the wheel tracking machine DYNA-TRACK which is used to assess the resistance to rutting of asphalt materials under conditions, which simulate the effect of traffic (Fig. 1) 8.

Air sampling from inside of the machine DYNA-TRACK during the rutting of samples is performed by equipment APS 3321 (Aerodynamic Particle Sizer) and SMPS 3080 (Scanning Mobility Particle Sizer) which intercept and distribute particle range from 0.012 to $20 \mu \mathrm{m}$ and 2 pieces of Leckel LVS3 which intercept particulate matter $\mathrm{PM}_{2.5}$ and $\mathrm{PM}_{1}$ on the nitrocellulose filters for the subsequent evaluation of mass concentrations and chemical analysis. The mixtures are rutted by typified wheel for 12 hours through the steady working conditions. It performs 20000 cycles during the 12 hours (i.e. 40000 running gears).

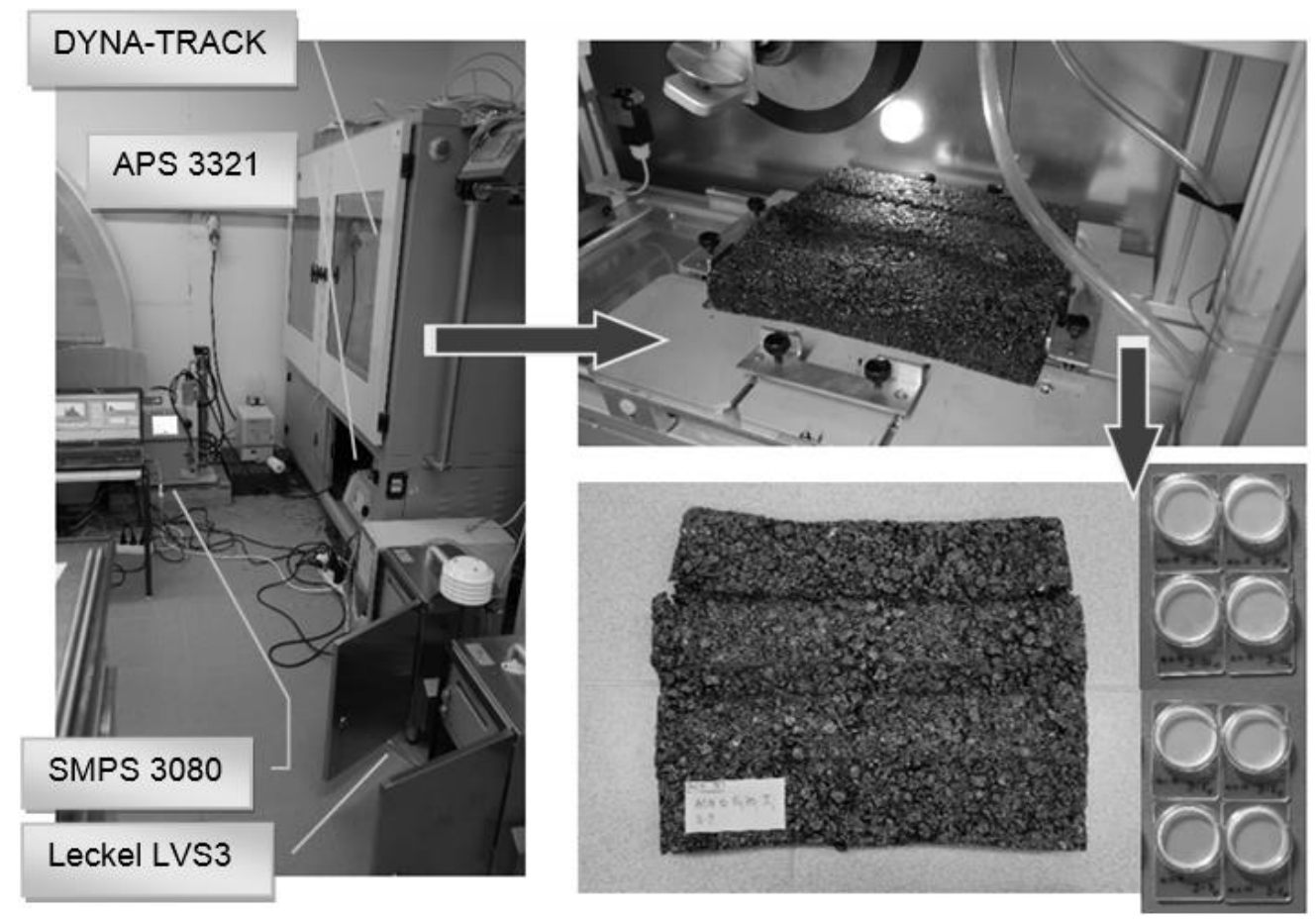

Fig. 1. The used machine technology and rutted asphalt mixture sample 
The tests of chemical composition of materials (aggregates, asphalt) of samples were carried out before the rutting of these asphalt mixture samples by XRF analyzer (X-ray fluorescence spectroscopy). For the experiments was used the machine SPEKTRO iQ II (AMATEK, Germany) in the laboratory of the Faculty of Civil Engineering of the Technical University in Košice. Chemical analysis of particulate matter intercepted on filters was carried out by ICP - MS - Inductively coupled plasma mass spectrometry in the laboratory at the Transport Research Centre in Brno. Imaging of PM was done by using the scanning electron microscope VEGA TS 5136 LSU (Tescan s.r.o., Czech Republic) that permits both low vacuum and high vacuum mode of measurements with resolution up to $3.5 \mathrm{~nm}$.

\section{Results of current laboratory tests}

Till now, the measurements of particulate matter were performed on six trial samples of asphalt mixtures with different composition. Two plates of each mixture were rutted in the laboratory and each plate was rutted two times. All six samples had the same conditions in the space of rutting during abrasion of asphalt mixtures. The total length of measurement was 12 hours. Marks of six rutted samples:

1. AC $11 O 50 / 70, I I, D-5$

- aggregate: quarry Tunezice (siliceous limestone), asphalt: CA 50/70

2. AC 11 O 50/70, II, $R-9$

- aggregate: quarry Biely Potok (dolomite), asphalt: CA 50/70

3. $A C 11 O P M B 45 / 80-75, I, R-8$

- aggregate: quarry Maluzina (melaphyre), quarry Biely Potok (dolomite),

- asphalt: PMB 45/80-75

4. AC $11 O 50 / 70, I I, K-4$

- aggregate: quarry Biely Potok (dolomite), quarry Badin (andesite),

- asphalt: CA $50 / 70$

5. AC 11 O 50/70, II, $S-9$

- aggregate: quarry Solosnica (melaphyre), quarry Trstin (dolomite),

- asphalt: CA 50/70

6. SMA 11 PMB 45/80 - 75, $S-4$

- aggregate: quarry Solosnica (melaphyre), quarry Trstin (dolomite),

- asphalt: PMB 45/80-75

\subsection{PM mass concentrations during the rutting of asphalt mixture samples}

The results of PM mass concentrations are shown in the following figure (Fig. 4). The highest concentrations were measured for the mixture with the mark $\mathrm{S}-9$ (AC 11 with classic bituminous binder) and the lowest concentrations of particulate matter were measured for the sample D - 5 (AC 11 with classic bituminous binder). The mixtures differ in the use of aggregate.

The concentrations were determined by two methods - spectrometers SMPS, APS and low volume sampler Leckel. The results correlate with each other - Leckel $\mathrm{PM}_{2.5}$ and SMPS+APS ( $\mathrm{r}=0.98)$ (Fig. 4). In the mixture with the highest concentrations the aggregates melaphyre and dolomite were used and in the mixture with the lowest concentrations the siliceous limestone was used. The average mass concentration of the 
sample S - 9 is by $6.30 \mu \mathrm{g} / \mathrm{m}^{3}$ higher than the average mass concentration of the sample D 5 . These concentrations were performed by means of SMPS and APS. By using gravimetric method the difference is determined at $5.36 \mu \mathrm{g} / \mathrm{m}^{3}$ for particulates of fraction $\mathrm{PM}_{2.5}$ and $4.77 \mu \mathrm{g} / \mathrm{m}^{3}$ for particulates of fraction $\mathrm{PM}_{1}$.

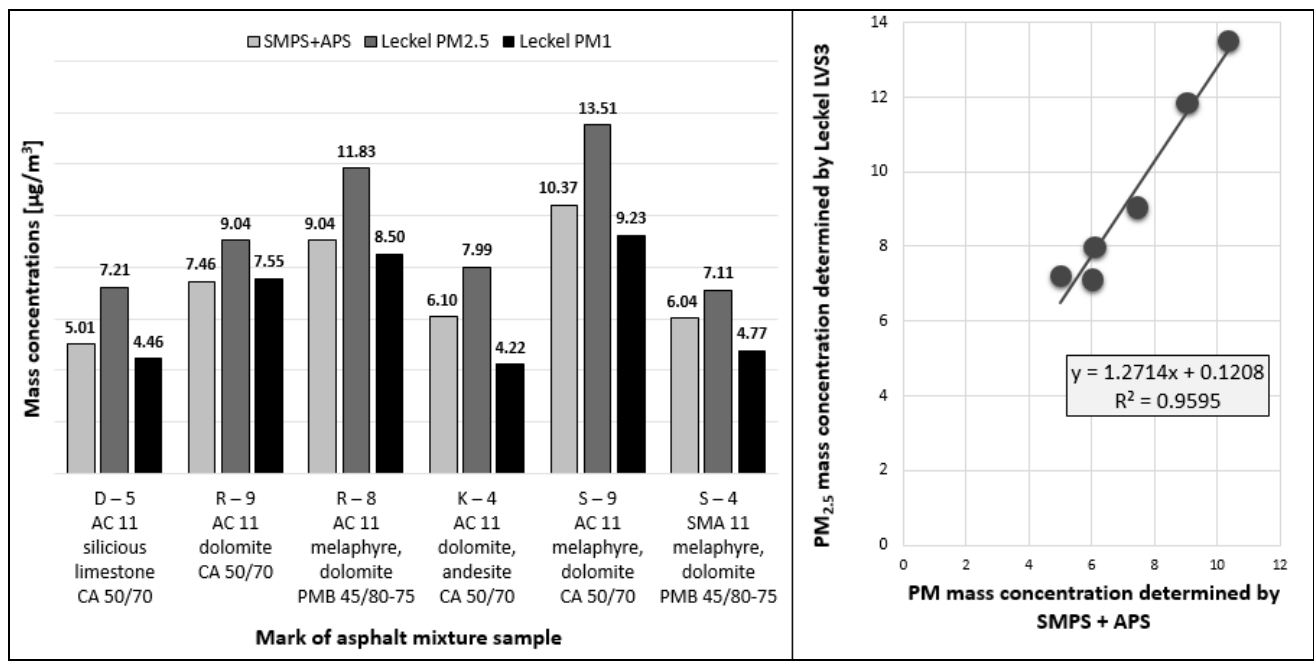

Fig. 2. The average measured PM mass concentrations and the correlation between PM mass concentrations determined by spectrometers (SMPS+APS) and low volume sampler (Leckel LVS3)

\subsection{Chemical composition of particulate matter}

For identification of particulate matter originating from the asphalt mixture abrasion the chemical composition of the basic materials of mixtures were carried out. The chemical elements (markers) were determined by analysis of the aggregate as a filler and the asphalt as a binder. Identified elements are subsequently confronted with the elements of the particulate matter collected on the filters.

It has been found that the bituminous binder contains approximately $4.8 \%$ of inorganic elements and organic elements are the rest. The sulphur $\mathrm{S}$ has the largest representation, it represents $4.19 \%$. The silicon $\mathrm{Si}(0.21 \%)$ and the chlorine $\mathrm{Cl}(0.17 \%)$ represent a higher share of identified inorganic elements.

The tests of chemical composition were also carried out for all kinds aggregates used in tested samples. In the samples the aggregates from six quarries were used (Maluzina, Badin, Solosnica, Biely Potok, Tunezice, Zirany). For XRF spectroscopy the powder samples (crushed aggregate) were used. From the analysis of materials the percentage of each selected element has been found. The results have shown that elements silicon Si and calcium $\mathrm{Ca}$ have the largest percentage in aggregates. The silicon $\mathrm{Si}$ predominates in aggregate from quarries Maluzina (melaphyre), Badin (andesite) and Solosnica (melaphyre) and the calcium $\mathrm{Ca}$ predominates in aggregate from quarries Biely Potok (dolomite), Tunezice (siliceous limestone), Zirany (limestone). The elements such as $\mathrm{Mg}, \mathrm{Al}, \mathrm{P}, \mathrm{Cl}$, and $\mathrm{K}$ represent a higher share of identified elements.

Chemical analysis of the exposed filters of particulate matter $\mathrm{PM}_{1}$ and $\mathrm{PM}_{2.5}$ was carried out by mass spectrometry with inductively coupled plasma ICP-MS. The principle of the device is that the samples are decomposed by acids by the action of microwaves. The prepared (decomposed) samples (51 filters) were analyzed for the presence of selected 13 
elements which have been determined by previous analyses of used aggregates and asphalt - Ca, Si, $\mathrm{Mg}, \mathrm{Al}, \mathrm{Fe}, \mathrm{P}, \mathrm{S}, \mathrm{Cl}, \mathrm{K}, \mathrm{V}, \mathrm{Cr}, \mathrm{Mn}, \mathrm{Na}$.

The following figure (Fig. 5) presents results of analyses of selected elements. Till now, 51 filters were analyzed. Two fraction of particulate matter were intercepted on these filters fraction $\mathrm{PM}_{1}$ and fraction $\mathrm{PM}_{2.5}$. For each mixture (2 plates, 4 ruttings) 4 filters of fraction $\mathrm{PM}_{1}$ and 4 filters of fraction $\mathrm{PM}_{2.5}$ were analyzed.

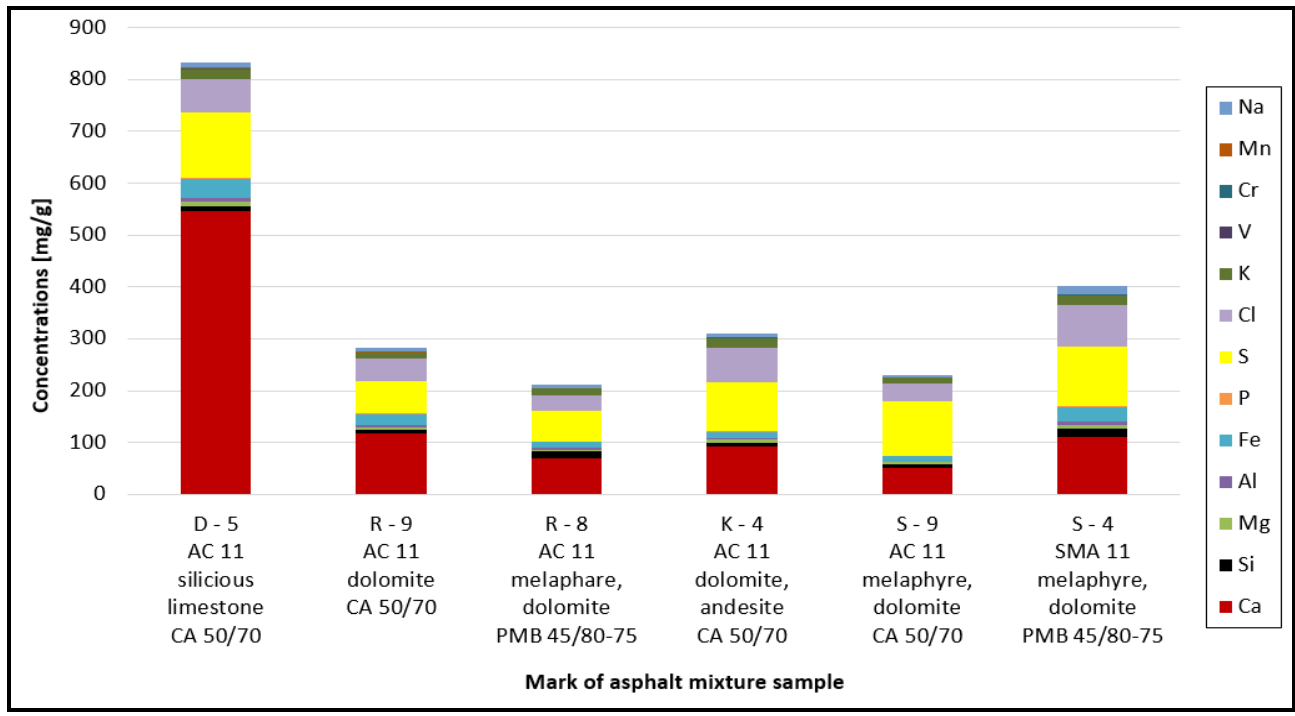

Fig. 3. The average mass concentrations of selected chemical elements in $\mathrm{PM}_{2.5}$ fraction

The elements $\mathrm{Ca}, \mathrm{S}, \mathrm{Cl}$ have the highest representation in the analysed filters. Calcium $\mathrm{Ca}$ has the highest representation in the sample with mark D - 5 and its concentration is 546.22 $\mathrm{mg} / \mathrm{g} \mathrm{PM}_{2.5}$. In this sample of asphalt mixture aggregate siliceous limestone is sued. Sulphur with mass concentration $126.15 \mathrm{mg} / \mathrm{g} \mathrm{PM}_{2.5}$ has also the highest concentration in the sample $\mathrm{D}-5$. With regard to the chlorine the highest concentration was measured in the sample $\mathrm{S}-4\left(81.47 \mathrm{mg} / \mathrm{g} \mathrm{PM}_{2.5}\right)$. On the other hand, the lowest concentrations were measured for the element vanadium $\mathrm{V}$ (in range from 0.01 to $0.04 \mathrm{mg} / \mathrm{g} \mathrm{PM}_{2.5}$ ) and for elements such as $\mathrm{Cr}, \mathrm{Mn}$ and $\mathrm{P}$. The highest concentrations of selected elements were analysed in the sample D -5 . Despite of the fact that the sample with mark D -5 has the lowest mass concentrations of particulate matter. Sample R - 9 presents the lowest mass concentrations of these elements and it is together $211.77 \mathrm{mg} / \mathrm{g}$ PM2.5. The aggregates rich in limestones are prone to polishing of its surface, the aggregates rich in feldspars have an average polishing and the aggregates rich in quartz are quite resistant to polishing. To exemplify, the highest mass concentration of calcium was measured in the sample in which the siliceous limestone is used.

As seen from the figure all selected elements occur in the intercepted particulates. It is obvious that the released particulates from surface abrasion have similar composition as the basic materials of asphalt mixtures (aggregate, bituminous binder).

\subsection{Morphology of abraded particulate matter}

Particulate matter (PM) is considered a mixture of chemical components originated from a variety of sources with specific physical parameters (such as shape, diameter, electric 
charge, solubility, surface of the particles) and chemical composition (organic and inorganic compounds). Sources, mechanisms of formation, meteorological conditions, distance from the source and other conditions determine these basic parameters 9. To gain a better understanding of PM origin and behaviour, it is necessary to describe their chemical composition and size distribution.

Imaging of PM was done by using the scanning electron microscope VEGA TS 5136 LSU (Tescan s.r.o., Czech Republic) in Transport Research Centre in Brno. Several types of filters are commonly used in sampling aerosols, but not all are compatible with SEM/EDX analysis 10. Particulate matter was intercepted on special filters with polycarbonate membrane.

Sharp-edged particles were observed on contaminated filters in a numerous representation. These particles can be characterized as fragments of geological materials (aggregates used in the mixtures). As a result, we can say that the particles are abraded from the mixtures during the rutting and the abrasion of aggregates used for asphalt mixtures could be the source of these particles.
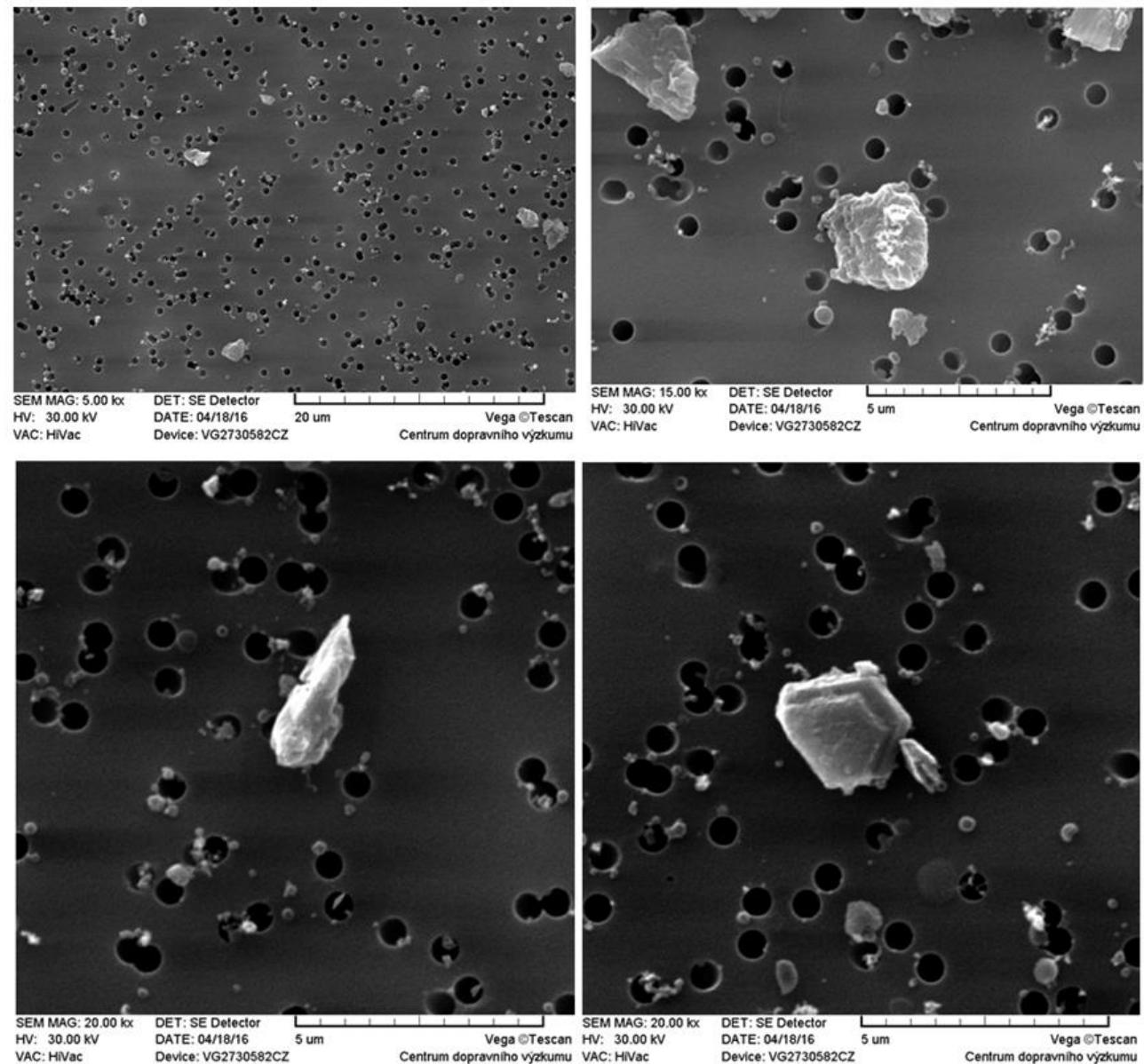

Fig. 4. Sharp-edged particles probably geological origin

Scanning electron microscope (SEM) may be used to determine the possible sources based on the size and shape of the particles. Nevertheless, for more proper PM sources identification it is suitable to combine the knowledge on separate PM morphology with the 
chemical composition of PM. PM origin interpretation only on the basis of morphology characterization without the chemical composition knowledge could be in some cases inaccurate or misleading.

Abrasion of individual components of the mixtures must be confirmed by means of chemical analysis of the particulates collected on nitrocellulose filters and its subsequent comparison with the composition of each tested mixture. Thus, obtained results presented in this paper were compared with data published in scientific literature 9, 10 in which the same PM shapes were observed and assigned to specific source.

\section{Discussion to the current results}

Primordial laboratory measurements of abrasion of asphalt mixture samples were carried out. Number and mass concentrations of particulate matter released during rutting of selected samples were measured. The tests of chemical composition of sample materials (aggregates, asphalt) were carried out before the rutting of these asphalt mixture samples by $\mathrm{XRF}$ analyzer (X-ray fluorescence spectroscopy). Also, the chemical analyses of particulate matter intercepted on filters were carried out by ICP - MS (Inductively coupled plasma mass spectrometry).

So far, 24 tests were performed for 6 samples of asphalt mixtures. It follows that each asphalt mixture had 4 available measurements. The mixtures differ in the use of aggregate and bituminous binder. The highest concentrations were measured for the mixture with mark S - 9 (AC 11 with classic bituminous binder) and the lowest concentrations of particulate matter were measured for the sample D - 5 (AC 11 with classic bituminous binder). In the mixture with the highest concentrations the aggregates melaphyre and dolomite were used and in the mixture with the lowest concentrations the siliceous limestone was used.

Imaging of PM was done by using the scanning electron microscope. Scanning electron microscopy (SEM) is an effective tool for the identification of PM sources. However, for more proper PM sources identification it is suitable to combine the knowledge on separate PM morphology with the chemical composition of PM. For examination the particulate matter shapes and sizes from abrasion of asphalt mixture surfaces the electron microscope was used. In numerous representation sharp-edged particles were observed on the filters, probably fragments of geological origin. Therefore we can say that the particulate matter are abraded from asphalt mixture surfaces and it may originate from abrasion of aggregates used in the mixtures.

From chemical analyses a number of facts about content of individual elements in the investigated materials has been revealed. The elements $\mathrm{Si}$ and $\mathrm{Ca}$ have majority representation in the aggregates. The elements of the under-representation in the aggregates are $\mathrm{Mg}, \mathrm{Al}$, and $\mathrm{Fe}$. The bituminous binder contains primarily elements of organic chemistry but sulphur $\mathrm{S}$ is majority element from inorganic elements.

From PM chemical analyses the average mass concentrations of selected chemical elements were found for each tested sample. The elements $\mathrm{Ca}, \mathrm{S}, \mathrm{Cl}$ have the highest representation in the analysed filters. Calcium $\mathrm{Ca}$ has the highest representation in the sample with mark D -5 and in this sample the aggregate siliceous limestone is sued. On the other hand, the lowest concentrations were measured for the element vanadium $\mathrm{V}, \mathrm{Cr}, \mathrm{Mn}$ and $\mathrm{P}$. As resulting, the released particulates from surface abrasion have similar composition as the basic materials of asphalt mixtures (aggregate, bituminous binder).

The aim of experimental measurements is to confirm the abrasion of pavement surface as a source of particulate matter and to verify the impact of the composition of asphalt mixture for the PM production during the rutting of samples. The findings from chemical analyses will be further applied in the next phase of research and used for verification of this impact. 
The measurements are still being continued and next assessment of PM concentrations and contents of selected elements in PM are expected in order to compare the asphalt mixtures with each other in terms of production PM.

\section{Acknowledgements}

The paper is a result of research supported by research project $K E G A$ 045Z̆U-4/2017 Environmental education of engineers for application in public administration.

\section{References}

1. Ďurčanská, D., et al., Analysis of methods of evaluation of the air pollution from road traffic: analysis task. Žilina: Faculty of Civil Engineering, Department of Highway Engineering (2014).

2. Amato, F., et al., Urban air quality: The challenge of traffic non-exhaust emissions. Journal of hazardous materials, 275, 31-36. (2014). Retrieved from www.scopus.com

3. Jandacka, D. : Contributory assessment of creation of PM10 as impacted by vehicular traffic based on the presence of heavy metals In: Communications : scientific letters of the University of Žilina. - ISSN 1335-4205. - Vol. 15, no. 3 p. 96-101, (2013).

4. Folkeson, et al., Spens: Sustainable Pavements for European New Member States, Guidelines for the environmental assessment of various pavement types including recommendations to road authorities in NMS, European commission DG research, Sixth framework programme, (2009).

5. Gehrig, R., Zeyer, K., Bukowiecki, N., Lienemann, P., Poulikakos, L. D., Furger, M., \& Buchmann, B., Mobile load simulators - A tool to distinguish between the emissions due to abrasion and resuspension of PM10 from road surfaces. Atmospheric Environment, 44(38), 4937-4943, (2010).

6. Gustafsson, M., Blomqvist, G., Gudmundsson, A., Dahl, A., Jonsson, P., \& Swietlicki, E., Factors influencing PM10 emissions from road pavement wear. Atmospheric Environment, 43(31), 4699-4702, (2009).

7. Pirjola, L., Kupiainen, K. J., Perhoniemi, P., Tervahattu, H., \& Vesala, H. Non-exhaust emission measurement system of the mobile laboratory SNIFFER. Atmospheric Environment, 43(31), 4703-4713, (2009).

8. Tervahattu, H., Kupiainen, K. J., Räisänen, M., Mäkelä, T., \& Hillamo, R., Generation of urban road dust from anti-skid and asphalt concrete aggregates. Journal of Hazardous Materials, 132(1 SPEC. ISS.), 39-46, (2006).

9. Wheel tracking machine DYNA-TRACK. Cernusco, Italy: Controls S.R.L., (2000).

10. Ličbinský, R., Frýbort, A., Huzlík, J., Adamec, V., Effenberger, K., Mikuška, P., Vojtěšek, M., Křŭmal, K. Usage of Scanning Electron Microscopy for Particulate Matter Sources Identification. Transactions on transport sciences, Number 3/2010. Ministry of Transport, p. 137-144. ISSN 1802-9876. (2010).

11. Willis, Robert D., Blanchard, Fredrick T., Conner, Teri L. Guidelines for the Application of SEM/EDX Analytical Techniques to Particulate Matter Samples. EPA \# 600/R-02/070. (2002). 